http://economix.fr

\title{
Towards Greater Diversification in Central Bank Reserves
}

Document de Travail

Working Paper

2015-34
Marie Brière

Valérie Mignon Kim Oosterlinck Ariane Szafarz

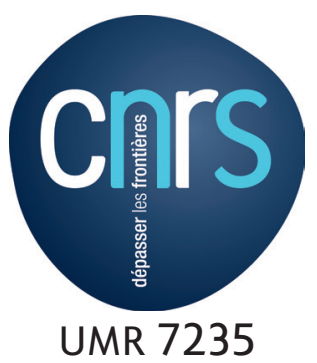

UMR 7235
Université de Paris Ouest Nanterre La Défense (bâtiment G)

200, Avenue de la République 92001 NANTERRE CEDEX université

Paris Ouest

Nanterre La Défense 


\title{
Towards Greater Diversification in Central Bank Reserves
}

\author{
Marie Brière* \\ Amundi, Paris Dauphine University, \\ and Université Libre de Bruxelles (ULB), SBS-EM, CEB \\ marie.briere@amundi.com \\ Valérie Mignon \\ EconomiX-CNRS, University of Paris Ouest and CEPII \\ valerie.mignon@u-paris10.fr \\ Kim Oosterlinck \\ Université Libre de Bruxelles (ULB), SBS-EM, CEB \\ koosterl@ulb.ac.be \\ Ariane Szafarz \\ Université Libre de Bruxelles (ULB), SBS-EM, CEB, and CERMi \\ aszafarz@ulb.ac.be
}

November 2015

\begin{abstract}
This paper compares the performance of various diversification strategies regarding foreign exchange reserves. The aim is to provide central banks with guidelines in portfolio allocation. We pay particular attention to the situation of upward pressures on U.S. interest rates by implementing our analysis over both the whole 1986-2015 period and a rising rate subsample. Relying on geometric tests of mean-variance efficiency, we show that introducing currencies weakly correlated to the USD (AUD and CAD) significantly reduces portfolio risk. Expected return is improved through mortgage-backed securities, corporate bonds, and equities.
\end{abstract}

Keywords: Foreign exchange reserves; diversification; asset allocation.

JEL codes: F31, G11, G15, E58.

* Corresponding Author: Address: Amundi, 91 Boulevard Pasteur, 75015 Paris, France, Phone: +33.1.43.23.91.61. 


\section{Introduction}

Central banks' foreign exchange (forex) reserves are massively held in U.S. dollars (USD), ${ }^{1}$ particularly in the form of short- to medium-run government bonds. According to data released by the International Monetary Fund (IMF), the USD share in global forex reserves represented, on average, $63 \%$ of total reserves at the end of $2014 .^{2}$ This strategy has proven highly profitable during the last 30 years, a period of declining interest rates. Today, however, U.S. rates are historically low, exposing central banks to a major interest-rate risk. Should the Federal Reserve raise rates, the value in USD of forex reserves could suffer substantial losses. Therefore, the risk associated with hiking rates should not be underestimated. To address the issue, this paper investigates the asset allocation of central bank reserves in a risk-return perspective, and compares the diversification benefits of competing investment opportunities.

Even if the share of U.S. dollar-denominated Treasury bonds remains predominant in forex reserves, several central banks, such as New Zealand's, have started to diversify their holdings with the twofold aim of earning returns above those of U.S. Treasuries, and reducing exposure to a rise in interest rates (Ramaswamy, 2008; McCauley and Rigaudy, 2011; Jones, 2014). The increase in U.S. current-account and fiscal deficits have also stepped up the pressure on central banks to diversify away from the USD.

Central banks have access to two diversification strategies. First, they can invest in asset classes that are more profitable than U.S. bonds and less sensitive to interest-rate risk. For instance, while its forex reserves are mainly held in U.S. Treasuries, the China State Administration of Foreign Exchange (SAFE) has been reducing its exposure by investing in various asset classes (U.S. agency bonds, corporate bonds and equities) since the mid-2000s. To achieve this objective the SAFE relies on its New York office, which invests in U.S. assets, real estate, and private equity (Wei and Cui, 2013). Likewise, the Bank of Japan has recently invested in exchange traded funds to boost its equity exposure. As for the Swiss

\footnotetext{
${ }^{1}$ This is the case for most worldwide central banks, with the notable (and evident) exception of the U.S. Federal Reserve. In this paper, we disregard the special situation of the Federal Reserve.

${ }_{2}$ See Currency Composition of Official Foreign Exchange Reserves (COFER): http://data.imf.org/?sk=E6A5F467-C14B-4AA8-9F6D-5A09EC4E62A4. Foreign currency diversification is still weak, the claims in the different currencies being as follows at the end of 2014: $22 \%$ in euro (EUR), around 4\% in British pound (GBP) and Japanese yen (JPY), close to $2 \%$ in Canadian dollar (CAD) and Australian dollar (AUD), and $0.3 \%$ in Swiss franc (SWI). Around $93 \%$ of foreign exchange reserves are invested in just four currencies: USD, EUR, JPY, and GBP.
} 
National Bank, equities now represent $16 \%$ of its reserves (Plender, 2014). ${ }^{3}$ Second, although the USD remains the unchallenged reserve currency, ${ }^{4}$ non-U.S. central banks implement currency diversification strategies (Chinn, 2014). Investments include government bonds in G4 currencies (USD, EUR, GBP, JPY), or a portfolio of these currencies with various possible weighting schemes such as the long-established Special Drawing Rights (SDR). ${ }^{5}$ Some central banks hold other major currencies, such as the Australian (AUD) or the Canadian $(\mathrm{CAD})^{6}$ dollars, but also emerging currencies, such as the Korean won (KRW), Brazilian real (BRL), Polish złoty (PLN), and Chinese renminbi (RMB). Diversification strategies are applied by central banks in both developed and developing countries. For example, those of Nigeria, Chile, and South Korea hold RMB reserves.

The objectives of central banks' reserves include: facilitating international trade, ensuring the liquidity of financial markets, easing interventions on the forex market, supporting the domestic currency, and maintaining the market's trust in the country's ability to repay its foreign debt. Plausibly, these objectives explain the composition of the banks' foreign reserves. Beck and Rahbari (2011) consider that the USD may be a safe haven during "sudden stops". 7 This would explain why several countries hold the currency in substantial amounts. Beck and Weber (2011) show that many central banks focus on supposedly risk-free assets, and exhibit a behavior driven by precautionary motives. However, some scholars emphasize the benefits of diversification. Ben-Bassat (1980) determines the optimal forex portfolio in a mean-variance framework. ${ }^{8}$ Wooldridge (2006) shows that central banks are gradually diversifying their allocations into corporate bonds, equities and non-traditional currencies, such as the CAD and AUD. Borio et al. (2008) point out that central banks are increasingly concerned with profitability, along with traditional objectives related to liquidity and safety; they gradually shift asset allocation to riskier assets exposed to credit and liquidity risks. Forex reserves are sometimes used to create a separate fund, independent from the central

\footnotetext{
${ }^{3}$ Other examples include the Bank of Israel and the Czech National Bank, which have also raised their equity exposures to more than $10 \%$ of reserves.

${ }^{4}$ See the so-called "exorbitant privilege" (Eichengreen, 2011; Cova et al., 2015).

${ }^{5}$ The SDR is an interest-bearing international reserve asset created by the IMF in 1969 to supplement other reserve assets of member countries. The SDR is based on a basket of international currencies comprising the U.S. dollar, Japanese yen, euro and pound sterling. https://www.imf.org/external/np/exr/faq/sdrallocfaqs.htm

${ }^{6}$ Many central banks are planning to increase their holdings of advanced country currencies, which are not part of the SDR basket (Morahan and Mulder, 2013).

${ }^{7} \mathrm{~A}$ "sudden stop" is an abrupt reduction in private capital inflows.

${ }^{8}$ According to Ben-Bassat (1980), the composition of developed countries' reserves is mainly influenced by the stability of the international monetary system, whereas developing countries care mainly about the profitability and liquidity of their reserves.
} 
bank's balance sheet, with the aim of making returns through efficient management of part of these holdings. ${ }^{9}$ Eichengreen and Flandreau (2014) confirm that central banks tend to adopt active forex management practices similar to those of private financial institutions.

This paper investigates the potential diversification strategies of a central bank. As a starting point, we consider three "benchmark" investment strategies widely used by central banks for reserve allocation: (i) investment exclusively in U.S. government bonds (1 to 5 years), (ii) investment in G4 government bonds ( 1 to 5 years) in the following representative proportions: $63 \%$ in USD, $22 \%$ in EUR, $4 \%$ in GBP, and $4 \%$ in JPY, ${ }^{10}$ and (iii) investment in G4 government bonds ( 1 to 5 years), with proportions corresponding to the weight of each currency in the SDR basket: $47 \%$ USD, 34\% EUR, 12\% GBP and 7\% JPY. ${ }^{11}$ The last of these approaches echoes the IMF's statement that "an SDR allocation is a low cost way of adding to members' international reserves, allowing members to reduce their reliance on more expensive domestic or external debt for building reserves". ${ }^{12}$

We challenge these three benchmark reserve allocations with optimized portfolios in various investment universes. First, we consider the optimal portfolio invested in the G4 currencies only. This allocation meets the liquidity objective of forex reserves. Under current market conditions, however, it has two major drawbacks: low profitability and high sensitivity to the risk of a rise in interest rates. Second, to overcome these drawbacks, we consider three alternative asset allocations in larger universes made up of: G4 currencies plus CAD and AUD (referred to as "G6 currencies"); G4 currencies plus other asset classes that have been included or considered for inclusion by many central banks (McCauley and Fung, 2003; Morahan and Mulder, 2013; Jones, 2014), namely U.S. mortgage-backed securities, corporate bonds (investment grade and high yield), and equities; ${ }^{13}$ and finally G6 currencies plus all the other asset classes.

\footnotetext{
${ }^{9}$ Some examples are Korea Investment Corporation and China Investment Corporation, respectively launched in 2005 or 2007.

${ }^{10}$ These shares correspond to the IMF average allocation of central banks in the G4 currencies (data collected in 2014, see footnote 2). These four currencies serve as the reference for the SDR and are now mostly used by central banks to diversify their foreign exchange reserves (Morahan and Mulder, 2013).

${ }^{11}$ See https://www.imf.org/external/np/fin/data/rms_sdrv.aspx. These figures are those of June 2015.

$12 \mathrm{https} / / /$ www.imf.org/external/np/exr/faq/sdrallocfaqs.htm. Moreover, Medeiros and Nocera (1988) show that the SDR plays a key role in central banks' reserve allocation.

${ }^{13}$ We consider diversification in the U.S. assets only. The mortgage-backed securities market is much less developed in non-US countries, and the high yield Japanese market is almost inexistent. Moreover, corporate bond markets and equity markets have a relatively high correlation across the different geographical zones (Brière et al., 2012). US corporate bonds and stock returns may be a good proxy for international returns.
} 
To assess the performances of diversification strategies, we compare their mean-variance (MV) efficient frontiers built from monthly returns over the 1986-2015 period. Our empirical design relies on two geometric tests of MV efficiency. The test proposed by Basak et al. (2002) is based on the "horizontal distance" between the portfolio whose MV efficiency is in question and its same-return counterpart on the MV efficient frontier. In contrast, the "vertical test" proposed by Brière et al. (2013) uses the difference between the portfolio's expected return and the expected return of its same-variance counterpart on the MV efficient frontier. After performing full-sample estimations and tests, we specifically address the current concern of potentially rising U.S. interest rates by restricting the data to the sub-periods of rate hiking only.

As expected, our results confirm that diversification improves asset allocation, in particular in terms of risk exposure. Central banks are no exception to this basic financial principle. Over the long term, the optimal risk-reducing strategy consists in increasing the share of U.S. government bonds, and diversifying the portfolio into currencies weakly correlated with USD, such as GBP, AUD, and CAD. To increase expected returns, the strategy is tilted toward asset classes such as mortgage-backed securities, corporate bonds, and equities. In times of rate hiking, risk can be reduced through a similar currency diversification strategy focused on GBP, JPY, and AUD. Higher expected returns are obtained by introducing either risky asset classes - especially high-yield corporate bonds and equities, which are relatively insensitive to interest-rate risk - or Treasury bonds in foreign currencies - JPY, GBP, AUD and CAD that outperform those in EUR and USD in times of rate hikes. Evidently, the central bank's ability to implement those strategies is subject to the legal constraints it is facing. Some are barred from investing in given asset classes. For instance, parts of the reserves are held to match imports. This is the case of China (Pan and Junbo, 2008). ${ }^{14}$ Overall, our results confirm that diversification of forex reserves deserves to be taken seriously, especially-but not only — when the risk of rate hiking is high.

The rest of the paper is organized as follows. Section 2 presents the data and provides descriptive statistics. Section 3 displays our results. Section 4 concludes.

\footnotetext{
${ }^{14}$ Goldberg et al. (2013) describe the strategies of other central banks.
} 


\section{Data and Descriptive Statistics}

\subsection{Data}

The analysis relies on monthly data covering the period from January 1986 to June 2015 . We consider short-term governments bonds (1 to 5 years, Merrill Lynch index) in USD, EUR, GBP, JPY, CAD, and AUD extracted from Bloomberg; mortgage-backed securities (Barclays U.S. indexes); corporate bonds (investment grade and high-yield, Barclays U.S. indexes); and equities (U.S. MSCI index) taken from Datastream.

Due to the current fears of a hike in rates, we pay special attention to periods of rising U.S. interest rates (federal funds rates). To identify these periods, we rely on a smoothing procedure. Specifically, any date framed by two months with rate increases is assumed to be an increase date. Conversely, a month with an "isolated" hike is disregarded. ${ }^{15}$ The hiking periods are displayed in Fig. 1, together with the corresponding fed funds rates.

Figure 1. U.S. interest rates and hiking periods, 1986-2015

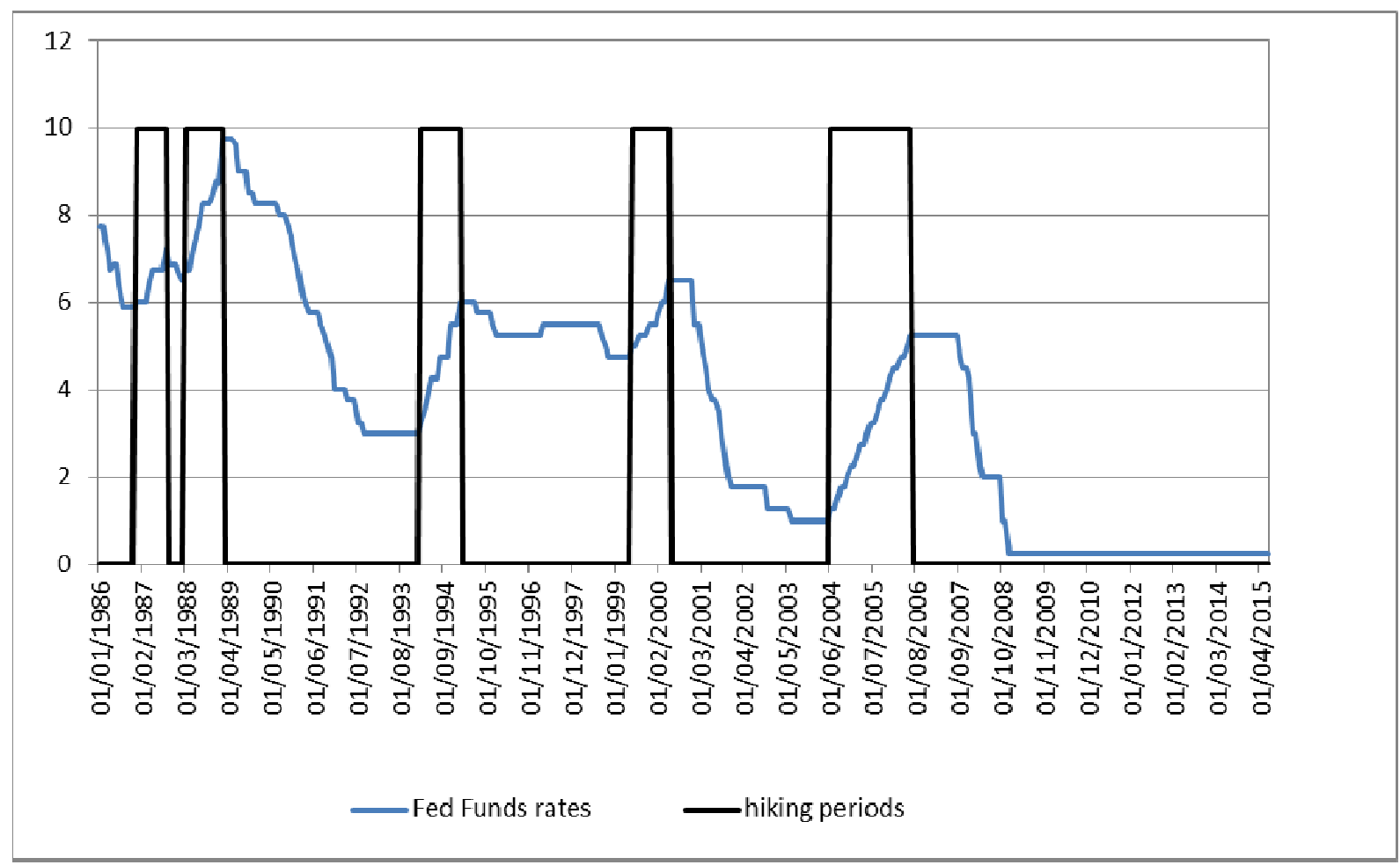

Source: Authors' calculations. U.S. interest rates are Fed funds rates extracted from Bloomberg.

\footnotetext{
${ }^{15}$ In fact, our sample comprises only two dates with isolated rises in interest rates, namely May 1986 and March 1997. Moreover, Fig. A1 in Appendix A shows that in times of U.S. rate hikes, non-U.S. central banks tend to increase their rates as well, especially in Canada and in the Eurozone.
} 
In line with most of the literature, we consider USD as the numeraire for central banks' reserve allocations (Bernadell et al., 2004). ${ }^{16}$

\subsection{Descriptive Statistics}

Table 1 provides the full-sample summary statistics. The short-term government bond investments in G4 currencies provide annual returns ranging from 5.15\% for JPY to $7.57 \%$ for GBP. The AUD and CAD offer attractive returns, with annual averages of $9.26 \%$ and $7.12 \%$, respectively. The average annual returns of the other assets range between $6.70 \%$ and $11.28 \%$, with volatilities between $2.41 \%$ (for the USD) and $15.25 \%$ (for the equities). Unsurprisingly, most assets exhibit the stigma of non-normal return distributions, as attested by the Jarque-Bera test statistics. In particular, the AUD and CAD government bonds, corporate bonds, and equities are characterized by negative skewness. The kurtosis of all asset classes is above the value of 3 that corresponds to normal distribution. The high yield corporate bond category exhibits the fattest tail, with a kurtosis reaching 11.67.

Table 2 displays the full-sample correlation matrix. The return on short-term government bonds in AUD is weakly correlated with that in USD (3\%) but not statistically significant. For CAD and JPY government bonds, the $8 \%$ correlation is also statistically insignificant. Both AUD and CAD bonds combine low risk (see Table 1) with promising diversification potential since their correlations with USD bonds are 3\% (but not significantly different from zero) and $19 \%$, respectively. Riskier assets, such as high-yield corporate bonds and equities, are negatively correlated with U.S. government bonds (ranging from $-5 \%$ to $-4 \%$ ). Since none of these correlations is statistically significantly different from zero, these assets are particularly interesting to include.

\footnotetext{
${ }^{16}$ It is worth mentioning that this choice is not benign since numeraires play a key role in asset allocation issues (Borio et al., 2008). Strictly speaking, the numeraire should depend on the use of forex reserves. For example, if the purpose of the reserves is to access imports under stress, then the numeraire could be a basket of imports. By contrast, if the reserves are meant to hedge the country's debt, the numeraire should be linked to the composition of the debt currency, which typically combines USD and domestic currency. Alternatively, the domestic currency could be used as the numeraire. This would meet central banks' concerns about the impact of fluctuations in the value of reserves on profitability and capital (Borio et al., 2008; Ramaswamy, 2008). As argued by Ramaswamy (2008, p. 46), "the reserves could also be viewed as domestic wealth whose value is to be maximized".
} 
Table 1. Descriptive statistics of monthly returns, whole sample 1986-2015

\begin{tabular}{|c|c|c|c|c|c|c|c|c|c|c|}
\hline & USD & EUR & GBP & JPY & AUD & CAD & MBS & CORP IG & CORP HY & EQUITIES \\
\hline Mean & $0.45 \%$ & $0.58 \%$ & $0.63 \%$ & $0.43 \%$ & $0.77 \%$ & $0.59 \%$ & $0.56 \%$ & $0.62 \%$ & $0.73 \%$ & $0.94 \%$ \\
\hline Ann. Mean & $5.38 \%$ & $6.98 \%$ & $7.57 \%$ & $5.15 \%$ & $9.26 \%$ & $7.12 \%$ & $6.70 \%$ & $7.39 \%$ & $8.74 \%$ & $11.28 \%$ \\
\hline Median & $0.39 \%$ & $0.68 \%$ & $0.55 \%$ & $0.14 \%$ & $1.05 \%$ & $0.65 \%$ & $0.58 \%$ & $0.70 \%$ & $0.95 \%$ & $1.32 \%$ \\
\hline Maximum & $2.58 \%$ & $10.51 \%$ & $10.44 \%$ & $17.04 \%$ & $8.80 \%$ & $7.75 \%$ & $3.93 \%$ & $6.80 \%$ & $12.10 \%$ & $13.28 \%$ \\
\hline Minimum & $-1.58 \%$ & $-10.05 \%$ & $-8.49 \%$ & $-10.23 \%$ & $-14.71 \%$ & $-11.09 \%$ & $-2.83 \%$ & $-7.77 \%$ & $-15.91 \%$ & $-21.22 \%$ \\
\hline Std. Dev. & $0.70 \%$ & $3.16 \%$ & $2.92 \%$ & $3.41 \%$ & $3.47 \%$ & $2.28 \%$ & $0.95 \%$ & $1.55 \%$ & $2.48 \%$ & $4.40 \%$ \\
\hline Volatility & $2.41 \%$ & $10.96 \%$ & $10.10 \%$ & $11.82 \%$ & $12.02 \%$ & $7.92 \%$ & $3.31 \%$ & $5.38 \%$ & $8.59 \%$ & $15.25 \%$ \\
\hline Skewness & 0.17 & -0.05 & 0.10 & 0.55 & -0.57 & -0.47 & 0.05 & -0.56 & -0.92 & -0.80 \\
\hline Kurtosis & 3.13 & 3.47 & 4.06 & 4.95 & 4.57 & 5.24 & 4.09 & 6.66 & 11.67 & 5.34 \\
\hline Jarque-Bera & 1.89 & 3.36 & 17.11 & 73.67 & 55.93 & 87.11 & 17.64 & 215.85 & 1157.38 & 118.59 \\
\hline Probability & 0.39 & 0.19 & 0.00 & 0.00 & 0.00 & 0.00 & 0.00 & 0.00 & 0.00 & 0.00 \\
\hline Observations & 354 & 354 & 354 & 354 & 354 & 354 & 354 & 354 & 354 & 354 \\
\hline
\end{tabular}

Note: USD: U.S. dollar, EUR: euro, GBP: British pound, JPY: Japanese yen, AUD: Australian dollar, CAD: Canadian dollar, MBS: mortgage-backed securities, CORP IG: investment grade corporate bonds, CORP HY: high-yield corporate bonds, EQUITIES: U.S. equities.

Table 2. Correlation matrix of monthly returns, whole sample 1986-2015

\begin{tabular}{|c|c|c|c|c|c|c|c|c|c|}
\hline & EUR & GBP & JPY & AUD & CAD & MBS & CORP IG & CORP HY & EQUITIES \\
\hline$\overline{U S D}$ & $29 \% * * *$ & $24 \% * * *$ & $30 \% * * *$ & $3 \%$ & $19 \% * * *$ & $85 \% * * *$ & $63 \% * * *$ & $-4 \%$ & $-5 \%$ \\
\hline EUR & & $69 \% * * *$ & $44 \% * * *$ & $41 \% * * *$ & $38 \% * * *$ & $23 \% * * *$ & $29 \% * * *$ & $13 \% * *$ & $8 \%$ \\
\hline GBP & & & $40 \% * * *$ & $35 \% * * *$ & $35 \% * * *$ & $19 \% * * *$ & $23 \% * * *$ & $10 \% * *$ & $6 \%$ \\
\hline JPY & & & & $14 \% * *$ & $8 \%$ & $20 \% * * *$ & $14 \% * * *$ & $-7 \%$ & $-5 \%$ \\
\hline AUD & & & & & $57 \% * * *$ & $11 \% * *$ & $30 \% * * *$ & $40 \% * * *$ & $37 \% * * *$ \\
\hline$C A D$ & & & & & & $29 \% * * *$ & $40 \% * * *$ & $45 \% * * *$ & $43 \% * * *$ \\
\hline MBS & & & & & & & $75 \% * * *$ & $17 \%^{* * *}$ & $11 \% * *$ \\
\hline CORP IG & & & & & & & & $51 \% * * *$ & $27 \% * * *$ \\
\hline CORP HY & & & & & & & & & $58 \% * * *$ \\
\hline
\end{tabular}

Note: USD: U.S. dollar, EUR: euro, GBP: British pound, JPY: Japanese yen, AUD: Australian dollar, CAD: Canadian dollar, MBS: mortgage-backed securities, CORP IG: investment grade corporate bonds, CORP HY: high-yield corporate bonds, EQUITIES: U.S. equities. *** (resp. **, *): significant at the 1\% (resp. 5\%, 10\%) statistical level.

Tables 3 and 4 give the same statistics but over the sub-period of U.S. rate hikes only. Table 3 shows that the short-term government bond investment in USD and EUR performs considerably less well than over the full sample, with average annual returns of $2.33 \%$ and $3.12 \%$, respectively. Both GBP and JPY bonds deliver attractive annual returns of around 7\% (7.09\% and 7.21\%, respectively). Interestingly, the annual returns on non-G4 bonds are even more attractive: $9.91 \%$ for AUD and $8.29 \%$ for CAD. Volatilities exhibit similar levels for all short-term government bond and mortgage-backed security investments. However one may notice a significant decrease in volatility for corporate bonds and equities (from $5.38 \%$ to $4.40 \%, 8.59 \%$ to $4.80 \%$, and $15.25 \%$ to $12.21 \%$ for investment grade and high-yield bonds, and equities respectively). Rising interest rates tend to coincide with a sustainable growth environment, which explains why both corporate bonds (especially high yield, very sensitive 
to the economic cycle) and equities exhibit attractive returns and lower volatility. Interestingly, the asset return distributions tend to be closer to normality over the rising rate periods than over the full sample period. Indeed, at the 5\% significance level, the Jarque-Bera test statistics reported in Table 3 reject the null hypothesis of normality for two asset classes only, namely the high-yield bonds and the equities.

Table 4 shows that correlations change dramatically during the hiking period. Some wholesample low correlations (Table 2) increase substantially. This is the case for the USD-CAD correlation (35\% in the hiking period v. $19 \%$ in the full sample) as well as for correlations between corporate bonds and equities. For example, the pairwise correlations of investment grade, high-yield corporate bonds and equities with U.S. short-term government bonds rise from whole-sample figures of $63 \%,-4 \%$ and $-5 \%$, respectively to hiking period values of 90\%, 49\% and 39\%, respectively. Conversely, EUR, GBP and JPY, which apparently provide limited diversification benefits in the whole sample (Table 2), are more attractive in a rate hiking environment. AUD stands out as the only currency weakly correlated with USD, no matter the period considered.

Table 3. Descriptive statistics of monthly returns, hiking period 1986-2015

\begin{tabular}{|c|c|c|c|c|c|c|c|c|c|c|}
\hline & USD & EUR & GBP & JPY & AUD & CAD & MBS & CORP IG & CORP HY & EQUITIES \\
\hline Mean & $0.19 \%$ & $0.26 \%$ & $0.59 \%$ & $0.60 \%$ & $0.83 \%$ & $0.69 \%$ & $0.22 \%$ & $0.10 \%$ & $0.35 \%$ & $1.03 \%$ \\
\hline Ann. Mean & $2.33 \%$ & $3.12 \%$ & $7.09 \%$ & $7.21 \%$ & $9.91 \%$ & $8.29 \%$ & $2.62 \%$ & $1.22 \%$ & $4.23 \%$ & $12.30 \%$ \\
\hline Median & $0.14 \%$ & $0.16 \%$ & $0.18 \%$ & $0.63 \%$ & $0.83 \%$ & $0.77 \%$ & $0.11 \%$ & $-0.17 \%$ & $0.56 \%$ & $1.01 \%$ \\
\hline Maximum & $1.69 \%$ & $6.28 \%$ & $8.17 \%$ & $7.82 \%$ & $8.17 \%$ & $5.21 \%$ & $2.85 \%$ & $2.88 \%$ & $4.14 \%$ & $13.28 \%$ \\
\hline Minimum & $-1.05 \%$ & $-5.98 \%$ & $-8.24 \%$ & $-6.60 \%$ & $-10.18 \%$ & $-4.38 \%$ & $-2.83 \%$ & $-3.29 \%$ & $-3.78 \%$ & $-5.35 \%$ \\
\hline Std. Dev. & $0.58 \%$ & $2.55 \%$ & $2.75 \%$ & $3.13 \%$ & $3.11 \%$ & $2.03 \%$ & $1.10 \%$ & $1.30 \%$ & $1.39 \%$ & $3.53 \%$ \\
\hline Volatility & $2.02 \%$ & $8.85 \%$ & $9.52 \%$ & $10.83 \%$ & $10.78 \%$ & $7.03 \%$ & $3.82 \%$ & $4.50 \%$ & $4.80 \%$ & $12.21 \%$ \\
\hline Skewness & 0.22 & -0.10 & 0.16 & 0.17 & -0.25 & -0.15 & 0.00 & -0.20 & -0.63 & 0.71 \\
\hline Kurtosis & 3.12 & 2.79 & 3.82 & 2.43 & 3.94 & 2.64 & 3.55 & 3.12 & 4.59 & 3.86 \\
\hline Jarque-Bera & 0.63 & 0.26 & 2.33 & 1.31 & 3.38 & 0.65 & 0.90 & 0.54 & 12.44 & 8.31 \\
\hline Probability & 0.73 & 0.88 & 0.31 & 0.52 & 0.18 & 0.72 & 0.64 & 0.76 & 0.00 & 0.02 \\
\hline Observations & 72 & 72 & 72 & 72 & 72 & 72 & 72 & 72 & 72 & 72 \\
\hline
\end{tabular}

Note: USD: U.S. dollar, EUR: euro, GBP: British pound, JPY: Japanese yen, AUD: Australian dollar, CAD: Canadian dollar, MBS: mortgage-backed securities, CORP IG: investment grade corporate bonds, CORP HY: high-yield corporate bonds, EQUITIES: U.S. equities. 
Table 4. Correlation matrix of monthly returns, hiking period 1986-2015

\begin{tabular}{|c|c|c|c|c|c|c|c|c|c|}
\hline & EUR & GBP & JPY & AUD & CAD & MBS & CORP IG & CORP HY & EQUITIES \\
\hline USD & $2 \%$ & $-4 \%$ & $1 \%$ & $-2 \%$ & $35 \% * * *$ & $91 \% * * *$ & $90 \% * * *$ & $49 \% * * *$ & $39 \% * * *$ \\
\hline EUR & & $72 \% * * *$ & $70 \% * * *$ & $20 \% *$ & $26 \% * *$ & $-3 \%$ & $0 \%$ & $14 \%$ & $5 \%$ \\
\hline GBP & & & $65 \% * * *$ & $38 \% * * *$ & $34 \% * * *$ & $-11 \%$ & $-6 \%$ & $3 \%$ & $3 \%$ \\
\hline JPY & & & & $19 \%$ & $14 \%$ & $-4 \%$ & $-1 \%$ & $-2 \%$ & $7 \%$ \\
\hline AUD & & & & & $38 \% * * *$ & $6 \%$ & $6 \%$ & $15 \%$ & $18 \%$ \\
\hline CAD & & & & & & $39 \% * * *$ & $39 \% * * *$ & $50 \% * * *$ & $42 \% * * *$ \\
\hline MBS & & & & & & & $93 \% * * *$ & $59 \% * * *$ & $45 \% * * *$ \\
\hline CORP IG & & & & & & & & $64 \% * * *$ & $40 \% * * *$ \\
\hline CORP HY & & & & & & & & & $49 \% * * *$ \\
\hline
\end{tabular}

Note: USD: U.S. dollar, EUR: euro, GBP: British pound, JPY: Japanese yen, AUD: Australian dollar, CAD: Canadian dollar, MBS: mortgage-backed securities, CORP IG: investment grade corporate bonds, CORP HY: high-yield corporate bonds, EQUITIES: U.S. equities. *** (resp. **, *): significant at the 1\% (resp. 5\%, 10\%) statistical level.

Let us now investigate in greater detail the risk-return profile associated with each investment strategy by calculating efficient frontiers and applying MV efficiency tests.

\section{Results}

Our three benchmark portfolios are: (i) U.S. government bonds only, (ii) G4 governments bonds with central banks' average proportions according to IMF (63\% USD, 22\% EUR, 4\% GBP, and 4\% JPY), and (iii) G4 government bonds, with SDR basket proportions (47\% USD, 34\% EUR, 12\% GBP, and 7\% JPY). The MV efficiency tests are based on distances between these portfolios and four distinct efficient frontiers. We consider frontiers corresponding to four investment universes: (i) G4 currencies; (ii) G6 currencies; (iii) G4 currencies plus U.S. mortgage-backed securities, corporate bonds, and equities; (iv) G6 currencies and the other asset classes. The analysis is performed first on the whole 1986-2015 period, and second on the rate hiking sub-period.

The MV approach assumes that the two first moments of the return multivariate distribution are sufficient to make meaningful decisions on asset allocation. On the other hand, our fullperiod descriptive statistics show that most return series exhibit serious non-normality relating to the moments of orders 3 and 4. That financial returns are non-normal is well-known, and constitute a potential cause for concern in any application of the MV approach. Despite this, MV-based studies continue to flourish in the literature for at least two reasons. First, the MV framework offers a two-dimensional representation that is both simple and appealing since it 
effectively captures the underlying intuition of the risk-return trade-off that investors have to face. Second, and perhaps more importantly, the MV approach is known to be robust against moderate non-normality (Levy and Markowitz, 1979). Therefore, going beyond a twomoment analysis is still a divisive issue.

We apply two MV efficiency tests. The first, developed by Basak, Jagannathan and Sun (2002) (henceforth, BJS), is based on the "horizontal distance" between the portfolio whose MV efficiency is in question and its same-return counterpart on the MV efficient frontier. Unfortunately, as stressed by Gerard et al. (2012), some portfolios lack such a counterpart, limiting the applicability of the BJS test. The second test, introduced by Brière et al. (2013), uses the "vertical distance" proposed by Kandel and Stambaugh (1995), Wang (1998), and Li et al. (2003), namely the difference between the tested portfolio's expected return and the expected return of its same-variance counterpart on the MV efficient frontier. Both tests are complementary, but the vertical test is more intuitive than the BJS one since it is based on a difference in return, which is more easily interpretable than a difference in variance. ${ }^{17}$

\subsection{Full-Sample}

Fig. 2 displays the efficient frontiers corresponding to the four investment universes over the whole period, together with the three benchmark portfolios. It shows that all these portfolios, made up of G4 currencies, are located close to the G4 efficient frontier. This means that the imposed proportions do not create inefficient portfolios but fix a level of risk that the central bank can no longer control. The least risky allocation is fully invested in USD, the second is the G4 average allocation, which includes $63 \%$ of USD, and the last is the G4 SDR basketbased portfolio, with a $47 \%$ share of USD.

For the G6 currencies, which include the core G4 currencies plus the non-core AUD and $\mathrm{CAD}$, we obtain a higher frontier. This highlights the benefits of currency diversification: for a same level of volatility, returns are always higher when investing in a broader sample of currencies is allowed. Adding other asset classes to the G4 currencies is even more interesting, since the corresponding efficient frontier is distinctly above the G6-only frontier.

\footnotetext{
${ }^{17}$ For more details on the two tests, see Brière et al. (2013).
} 
However, the full diversification strategy combining the G6 currencies and other asset classes delivers a frontier very close to the previous one. This suggests that including AUD and CAD provides no additional benefits once other assets are present in the investment universe. To sum up, for the representative central banks the most relevant strategy seems to be holding reserves in G4 currencies and in U.S. mortgages, investment grade and high-yield corporate bonds, and equities.

Figure 2. Benchmark portfolios and efficient frontiers, whole sample, 1986-2015

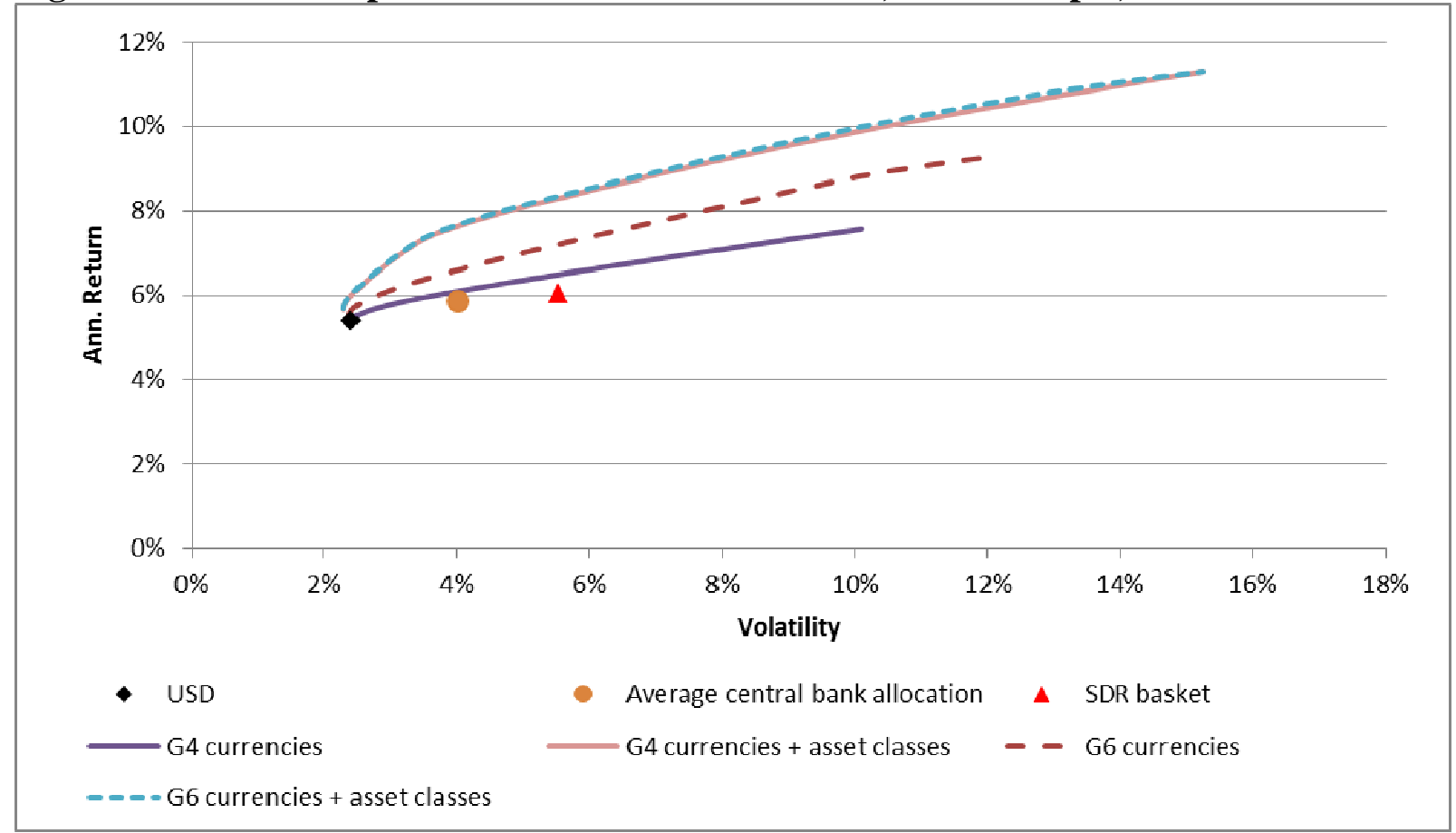

Source: Authors' calculations. 
Table 5. Results of BJS and vertical tests, whole sample, 1986-2015

\begin{tabular}{|c|c|c|c|c|c|c|c|c|c|c|c|c|}
\hline \multirow[b]{2}{*}{ Efficient frontier } & \multicolumn{4}{|c|}{ USD } & \multicolumn{4}{|c|}{ Central Banks Average Allocation } & \multicolumn{4}{|c|}{ SDR Basket } \\
\hline & $\begin{array}{c}\text { G4 } \\
\text { currencies } \\
\quad \text { (1) } \\
\end{array}$ & $\begin{array}{c}\text { G6 } \\
\text { currencies } \\
\quad \text { (2) }\end{array}$ & $\begin{array}{c}\mathrm{G} 4 \\
\text { currencies + } \\
\text { asset classes } \\
\text { (3) }\end{array}$ & $\begin{array}{c}\mathrm{G6} \\
\text { currencies + } \\
\text { asset classes } \\
\text { (4) }\end{array}$ & $\begin{array}{c}\text { G4 } \\
\text { currencies } \\
\text { (5) }\end{array}$ & $\begin{array}{c}\text { G6 } \\
\text { currencies } \\
\quad(6) \\
\end{array}$ & $\begin{array}{c}\text { G4 } \\
\text { currencies + } \\
\text { asset classes } \\
\text { (7) }\end{array}$ & $\begin{array}{c}\mathrm{G6} \\
\text { currencies + } \\
\text { asset classes } \\
\quad \text { (8) }\end{array}$ & $\begin{array}{c}\text { G4 } \\
\text { currencies } \\
\quad \text { (9) }\end{array}$ & $\begin{array}{c}\text { G6 } \\
\text { currencies } \\
\quad(10) \\
\end{array}$ & $\begin{array}{c}\mathrm{G} 4 \\
\text { currencies + } \\
\text { asset classes } \\
\quad \text { (11) }\end{array}$ & $\begin{array}{c}\text { G6 } \\
\text { currencies + } \\
\text { asset classes } \\
\quad(12)\end{array}$ \\
\hline \multicolumn{13}{|c|}{ Panel A: Distance to Efficient Frontier } \\
\hline Tested portfolio volatility & $2.41 \%$ & $2.41 \%$ & $2.41 \%$ & $2.41 \%$ & $4.00 \%$ & $4.00 \%$ & $4.00 \%$ & $4.00 \%$ & $5.52 \%$ & $5.52 \%$ & $5.52 \%$ & $5.52 \%$ \\
\hline Efficient portfolio volatility & $2.41 \%$ & - & - & - & $3.18 \%$ & $2.58 \%$ & $2.33 \%$ & $2.32 \%$ & $3.83 \%$ & $2.87 \%$ & $2.44 \%$ & $2.42 \%$ \\
\hline Horizontal distance & 0.00 & - & - & - & $4,87^{*}$ & $7,76^{* * *}$ & $8,79 * * *$ & $8,82^{* * *}$ & $13,11^{* *}$ & $18,5^{* * *}$ & $20,4^{* * *}$ & $20,45^{* * *}$ \\
\hline (T-stat) & $(0.00)$ & - & - & - & $(1,69)$ & $(5,55)$ & $(8,63)$ & $(8,81)$ & $(1,97)$ & $(5,55)$ & $(9,56)$ & $(9,68)$ \\
\hline Tested portfolio return & $5.38 \%$ & $5.38 \%$ & $5.38 \%$ & $5.38 \%$ & $5.84 \%$ & $5.84 \%$ & $5.84 \%$ & $5.84 \%$ & $6.04 \%$ & $6.04 \%$ & $6.04 \%$ & $6.04 \%$ \\
\hline Efficient portfolio return & $5.38 \%$ & $5.64 \%$ & $5.90 \%$ & $6.00 \%$ & $6.06 \%$ & $6.50 \%$ & $7.39 \%$ & $7.47 \%$ & $6.49 \%$ & $7.16 \%$ & $8.14 \%$ & $8.32 \%$ \\
\hline $\begin{array}{l}\text { Vertical distance } \\
\text { (T-stat) }\end{array}$ & $\begin{array}{c}0.00 \\
(0,10)\end{array}$ & $\begin{array}{c}0.00 \\
(1,57)\end{array}$ & $\begin{array}{c}0,01 * * * \\
(2,82)\end{array}$ & $\begin{array}{l}0,01 * * \\
(2,35)\end{array}$ & $\begin{array}{c}0.00 \\
(0,83)\end{array}$ & $\begin{array}{c}0.01 \\
(1,09)\end{array}$ & $\begin{array}{l}0,02 * * \\
(1,98)\end{array}$ & $\begin{array}{l}0,02 * * \\
(2,25)\end{array}$ & $\begin{array}{c}0.00 \\
(0,68)\end{array}$ & $\begin{array}{c}0.01 \\
(1,20)\end{array}$ & $\begin{array}{l}0,02^{*} \\
(1,80)\end{array}$ & $\begin{array}{l}0,02 * * \\
(1,96)\end{array}$ \\
\hline \multicolumn{13}{|c|}{ 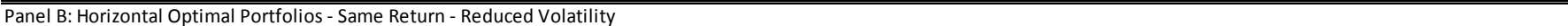 } \\
\hline USD & $100 \%$ & - & - & - & $79 \%$ & $86 \%$ & $87 \%$ & $88 \%$ & $70 \%$ & $79 \%$ & $77 \%$ & $78 \%$ \\
\hline MBS & - & - & - & - & - & - & $0 \%$ & $0 \%$ & - & - & $8 \%$ & $7 \%$ \\
\hline CorpIG & - & - & - & - & - & - & $0 \%$ & $0 \%$ & - & - & $0 \%$ & $0 \%$ \\
\hline CorpHY & - & - & - & - & - & - & $10 \%$ & $9 \%$ & - & - & $11 \%$ & $10 \%$ \\
\hline Equities & - & - & - & - & - & - & $2 \%$ & $1 \%$ & - & - & $3 \%$ & $2 \%$ \\
\hline EUR & $0 \%$ & - & - & - & $0 \%$ & $0 \%$ & $0 \%$ & $0 \%$ & $0 \%$ & $0 \%$ & $0 \%$ & $0 \%$ \\
\hline GBP & $0 \%$ & - & - & - & $21 \%$ & $2 \%$ & $1 \%$ & $0 \%$ & $30 \%$ & $4 \%$ & $2 \%$ & $1 \%$ \\
\hline JPY & $0 \%$ & - & - & - & $0 \%$ & $0 \%$ & $0 \%$ & $0 \%$ & $0 \%$ & $0 \%$ & $0 \%$ & $0 \%$ \\
\hline AUD & - & - & - & - & - & $10 \%$ & - & $2 \%$ & - & $13 \%$ & - & $2 \%$ \\
\hline CAD & - & - & - & - & - & $2 \%$ & - & $0 \%$ & - & $3 \%$ & - & $0 \%$ \\
\hline \multicolumn{13}{|c|}{ Panel C: Vertical Optimal Portfolios - Same Volatility - Improved Return } \\
\hline$\overline{\text { USD }}$ & $100 \%$ & $92 \%$ & $76 \%$ & $78 \%$ & $66 \%$ & $54 \%$ & $23 \%$ & $17 \%$ & $49 \%$ & $35 \%$ & $12 \%$ & $0 \%$ \\
\hline MBS & - & - & $16 \%$ & $6 \%$ & - & - & $25 \%$ & $33 \%$ & - & - & $17 \%$ & $25 \%$ \\
\hline CorpIG & - & - & $0 \%$ & $0 \%$ & - & - & $18 \%$ & $12 \%$ & - & - & $16 \%$ & $18 \%$ \\
\hline CorpHY & - & - & $5 \%$ & $10 \%$ & - & - & $17 \%$ & $12 \%$ & - & - & $19 \%$ & $18 \%$ \\
\hline Equities & - & - & $2 \%$ & $1 \%$ & - & - & $10 \%$ & $8 \%$ & - & - & $22 \%$ & $16 \%$ \\
\hline EUR & $0 \%$ & $0 \%$ & $0 \%$ & $0 \%$ & $11 \%$ & $0 \%$ & $1 \%$ & $0 \%$ & $0 \%$ & $0 \%$ & $5 \%$ & $0 \%$ \\
\hline GBP & $0 \%$ & $0 \%$ & $1 \%$ & $3 \%$ & $23 \%$ & $8 \%$ & $7 \%$ & $10 \%$ & $51 \%$ & $14 \%$ & $10 \%$ & $12 \%$ \\
\hline JPY & $0 \%$ & $0 \%$ & $0 \%$ & $0 \%$ & $0 \%$ & $0 \%$ & $0 \%$ & $0 \%$ & $0 \%$ & $0 \%$ & $0 \%$ & $0 \%$ \\
\hline AUD & - & $6 \%$ & - & $2 \%$ & - & $13 \%$ & - & $8 \%$ & - & $27 \%$ & - & $11 \%$ \\
\hline CAD & - & $2 \%$ & - & $0 \%$ & - & $25 \%$ & - & $0 \%$ & - & $24 \%$ & - & $0 \%$ \\
\hline
\end{tabular}

Note: Panel A presents the results of the BJS and vertical tests. Horizontal distance is the result of the BJS test, i.e. the difference in variance between the tested portfolio and the optimal portfolio with the same return on the efficient frontier multiplied by 10E5. Vertical distance is the result of the vertical test, i.e. the difference in return between the tested portfolio and the optimal portfolio of same variance on the efficient frontier multiplied by 12 to provide an annualized return. Panel B (resp. Panel C) displays the horizontal (resp. vertical) optimal shares of each currency and asset class. $* * *$ (resp. $* *, *)$ : significant at the $1 \%$ (resp. 5\%, 10\%) statistical level.

Fig. 2 provides visual evidence of diversification benefits. However, only proper tests can confirm the empirical relevance of this observation. Panel A in Table 5 displays the results of the BJS and vertical tests, and gives the compositions of optimal portfolios. As mentioned previously, it is not always possible to run the horizontal test due to the possible lack of the efficient same-return counterpart of the considered portfolio, hence the missing values for this test. In particular, when the tested portfolio is invested in USD only, the risk is very low-and there is no less-risky efficient portfolio. This limitation emphasizes the relevance of the vertical test, which does not suffer from the same technical limitation.

Considering first the full USD allocation (Columns (1)-(4)), our findings show that portfolio volatility cannot be reduced. However, higher returns can be obtained by extending the investment universe. The optimal asset allocation in G6 currencies contains only small proportions of AUD and CAD bonds (6\% and $2 \%$, respectively). Thus, currency 
diversification alone (Column (2)) cannot drive significant return improvements. However, adding other asset classes - mortgage-backed securities (16\%), high-yield corporate bonds $(5 \%)$ and equities (2\%)-leads to a higher return (from $5.38 \%$ to $5.90 \%$, Column (3)). This point is worth stressing, as more and more central banks are investing in diversified asset classes. Indeed, based on a survey conducted by the IMF, Morahan and Mulder (2013) estimate that more than $15 \%$ of central banks invest part of their reserves in equity. Introducing AUD and/or CAD in addition to other assets is not particularly useful, since the performance is only very slightly changed (Column (4)). Optimal asset allocations including both G6 currencies and diversifying asset classes have a very low proportion of non-G4 currency bonds (2\% AUD and $0 \%$ CAD).

Let us now turn to the central banks' average allocation in G4 currencies (Columns (5)-(8)). Portfolio volatility can be significantly reduced by two different moves: increasing the share of U.S government bonds, and enlarging the investment possibilities. For instance, when the share of U.S. government bonds is raised from $79 \%$ to $86 \%$, while simultaneously introducing $10 \%$ AUD and 2\% CAD, the portfolio's volatility drops from $4 \%$ to $2.58 \%$ (Column (6)). Volatility is even lower $(2.33 \%)$ if the central bank extends its reserves to high-yield corporate bonds (10\%) and equities (2\%) (Column (7)). The results confirm the intuition gained from Fig. 2: adding both other asset classes and non-core currencies (Column (8)) to G4 currencies barely reduces risk exposure. The optimal portfolio is however very different if the aim is to increase returns instead of reducing volatility. Contrasting with the low return performance of the two non-core currencies (Column (6)), return gains earned by including other asset classes are far from negligible (Column (7)). Indeed, the average return rises from $5.84 \%$ to $7.39 \%$ with the combined inclusion of U.S. mortgages $(25 \%)$, investment grade corporate bonds (18\%), high-yield corporate bonds (17\%), and equities (10\%). The highest score $(7.47 \%)$ is achieved by the full diversification strategy (Column (8)), which includes a substantial share of diversified asset classes (33\% mortgages, $12 \%$ investment grade corporate bonds, $12 \%$ high-yield corporate bonds, $8 \%$ equities) on top of $8 \%$ AUD, but no CAD.

Our third benchmark portfolio, based on the SDR basket (Columns (9)-(12)), can also be improved significantly. Risk can be easily reduced, from 5.52 to $3.83 \%$, by modifying the weights of the four core currencies (Column (9)), i.e. by increasing the share of USD (from $47 \%$ to $70 \%$ ) and GBP (12\% to $30 \%)$. Risk reduction based on currency diversification can be even larger, from $5.52 \%$ to $2.87 \%$, if AUD and CAD are included in the portfolio, with 
respective shares of $13 \%$ and $3 \%$ (Column (10)). Extending the investment universe to broad asset classes ( $8 \%$ mortgages, $11 \%$ high yield and 3\% equities) leads to better performances than the currency diversification strategy, since volatility decreases from $5.52 \%$ to $2.44 \%$ for a similar return (Column (11)). In addition, allowing for investment in AUD and CAD does not strongly modify these findings (a modest share of $2 \%$ AUD government bonds is added to the previous portfolio, obtained by slightly reducing exposure to mortgages, high yield and equities), since volatility amounts to $2.42 \%$ (Column (12)). Considering returns, the performance is significantly improved (from $6.04 \%$ to $8.32 \%$ ) only with the full diversification strategy. This is achieved through a wholly diversified portfolio including $25 \%$ mortgages, $18 \%$ investment grade and high-yield bonds, $16 \%$ equities, $12 \%$ GBP and $11 \%$ AUD short-term government bonds, ruling out USD government bonds from the asset allocation.

To sum up, the central banks' average allocation and the SDR basket-based allocation strategies are shown to be clearly inefficient and can be easily improved. It is easier to reduce volatility than to increase return, the former being achieved by augmenting the shares of USD and GBP, the latter by extending investment opportunities to non-core currencies and/or riskier asset classes. In particular, adding mortgage-backed securities, high-yield corporate bonds and equities is a useful strategy in terms of return improvement. Unless a central bank is obligated to invest in USD government bonds, our results show that there is room for improvement in a risk-return framework.

\subsection{Hiking Period}

We now conduct the same analysis but restrict the sample to the hiking period. Fig. 3 illustrates that our three benchmark portfolios are dominated by better-diversified portfolios lying on efficient frontiers. Currency and asset class diversifications provide little additional return for low-risk portfolios. By contrast, including G6 currencies in high-risk portfolios leads to a notable increase in expected returns. Overall, the most effective strategy combines both types of diversification.

Figure 3. Central bank reserve benchmark portfolios and efficient frontiers, hiking period, 1986-2015 


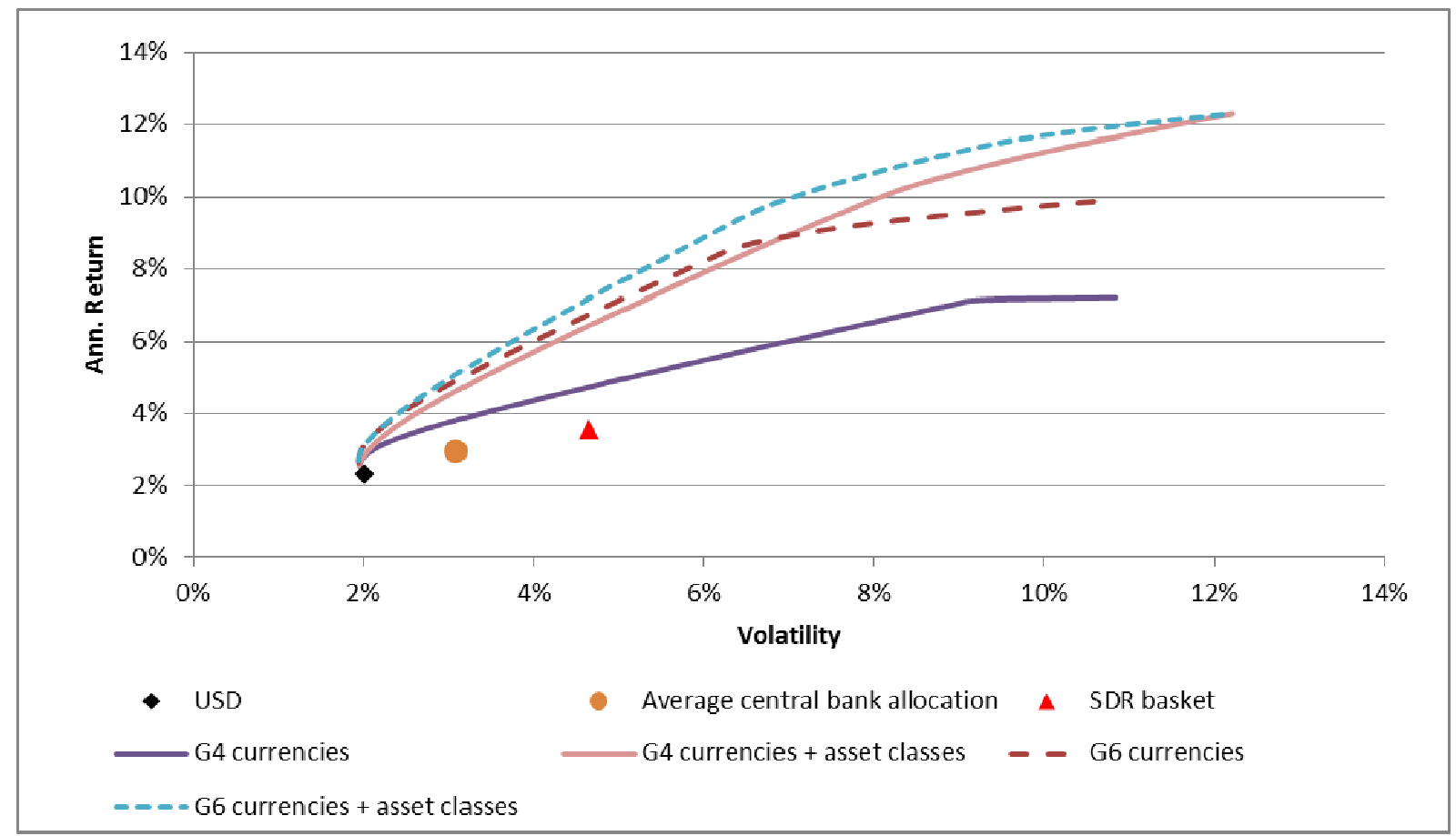

Source: Authors' calculations.

Table 6 shows that, even in the hiking period, improving a portfolio's return is easier than reducing its risk. Risk can indeed be dampened by allowing for greater flexibility in the shares of the core currencies and extending the investment opportunities. In all the cases presented in Table 6, the horizontal distance is significant at the $1 \%$ statistical level, whereas the vertical distance is significant, at best, at the $10 \%$ level (Columns (7), (8), and (12) in Panel A) and entails a considerable enlargement of the set of investment opportunities. 
Table 6. Results of BJS and vertical tests, hiking period, 1986-2015

\begin{tabular}{|c|c|c|c|c|c|c|c|c|c|c|c|c|}
\hline \multirow[b]{2}{*}{ Efficient frontier } & \multicolumn{4}{|c|}{ USD } & \multicolumn{4}{|c|}{ Central Banks Average Allocation } & \multicolumn{4}{|c|}{ SDR Basket } \\
\hline & 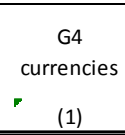 & $\begin{array}{c}\text { G6 } \\
\text { currencies } \\
\quad(2) \\
\end{array}$ & $\begin{array}{c}\text { G4 } \\
\text { currencies + } \\
\text { asset classes } \\
\text { (3) } \\
\end{array}$ & $\begin{array}{c}\text { G6 } \\
\text { currencies + } \\
\text { asset classes } \\
\text { (4) }\end{array}$ & $\begin{array}{c}\text { G4 } \\
\text { currencies } \\
\text { (5) }\end{array}$ & $\begin{array}{c}\text { G6 } \\
\text { currencies } \\
\quad(6) \\
\end{array}$ & $\begin{array}{c}\text { G4 } \\
\text { currencies + } \\
\text { asset classes } \\
\quad(7) \\
\end{array}$ & $\begin{array}{c}\text { G6 } \\
\text { currencies + } \\
\text { asset classes } \\
\text { (8) }\end{array}$ & $\begin{array}{c}\text { G4 } \\
\text { currencies } \\
\quad(9) \\
\end{array}$ & $\begin{array}{c}\text { G6 } \\
\text { currencies } \\
\quad(10) \\
\end{array}$ & $\begin{array}{c}\mathrm{G} 4 \\
\text { currencies + } \\
\text { asset classes } \\
\quad \text { (11) } \\
\end{array}$ & $\begin{array}{c}\text { G6 } \\
\text { currencies + } \\
\text { asset classes } \\
\quad(12) \\
\end{array}$ \\
\hline \multicolumn{13}{|c|}{ Panel A: Distance to Efficient Frontier } \\
\hline Tested portfolio volatility & $2.01 \%$ & $2.01 \%$ & $2.00 \%$ & $2.00 \%$ & $3.07 \%$ & $3.07 \%$ & $3.07 \%$ & $3.07 \%$ & $4.63 \%$ & $4.63 \%$ & $4.63 \%$ & $4.63 \%$ \\
\hline Efficient portfolio volatility & - & - & - & - & $2.06 \%$ & $1.95 \%$ & $2.03 \%$ & $1.95 \%$ & $2.69 \%$ & $2.18 \%$ & $2.32 \%$ & $2.17 \%$ \\
\hline Horizontal distance & - & - & - & - & $4,3^{* * *}$ & $4,67^{* * *}$ & $4,41^{* * *}$ & $4,67^{* * *}$ & $11,8^{* * *}$ & $13,9^{* * *}$ & $13,37 * * *$ & $13,93 * * *$ \\
\hline (T-stat) & - & - & - & - & $(3,158)$ & $(4,081)$ & $(3,692)$ & $(4,081)$ & $(2,788)$ & $(4,589)$ & $(4,287)$ & $(4,712)$ \\
\hline Tested portfolio return & $2.33 \%$ & $2.33 \%$ & $2.33 \%$ & $2.33 \%$ & $2.93 \%$ & $2.93 \%$ & $2.93 \%$ & $2.93 \%$ & $3.54 \%$ & $3.54 \%$ & $3.54 \%$ & $3.54 \%$ \\
\hline Efficient portfolio return & $2.83 \%$ & $3.12 \%$ & $2.86 \%$ & $3.12 \%$ & $3.30 \%$ & $4.88 \%$ & $4.62 \%$ & $5.07 \%$ & $4.73 \%$ & $6.75 \%$ & $6.43 \%$ & $7.19 \%$ \\
\hline $\begin{array}{l}\text { Vertical distance } \\
\text { (T-stat) }\end{array}$ & $\begin{array}{c}0.01 \\
(1,17) \\
\end{array}$ & $\begin{array}{c}0.01 \\
(1,47) \\
\end{array}$ & $\begin{array}{c}0.01 \\
(1,25) \\
\end{array}$ & $\begin{array}{c}0.01 \\
(1,54) \\
\end{array}$ & $\begin{array}{c}0.00 \\
(1,46) \\
\end{array}$ & $\begin{array}{r}0.02 \\
(1,52) \\
\end{array}$ & $\begin{array}{c}0,02 * \\
(1,67) \\
\end{array}$ & $\begin{array}{l}0,02 * \\
(1,76) \\
\end{array}$ & $\begin{array}{c}0.01 \\
(1,47) \\
\end{array}$ & $\begin{array}{c}0.03 \\
(1,62) \\
\end{array}$ & $\begin{array}{c}0.03 \\
(1,57) \\
\end{array}$ & $\begin{array}{c}0,04^{*} \\
(1,77) \\
\end{array}$ \\
\hline \multicolumn{13}{|c|}{ Panel B: Horizontal Optimal Portfolios - Same Return - Reduced Volatility } \\
\hline$\overline{U S D}$ & - & - & - & - & $87 \%$ & $90 \%$ & $87 \%$ & $90 \%$ & $75 \%$ & $81 \%$ & $78 \%$ & $81 \%$ \\
\hline MBS & - & - & - & - & - & - & $0 \%$ & $0 \%$ & - & - & $0 \%$ & $0 \%$ \\
\hline CorplG & - & - & - & - & - & - & $0 \%$ & $0 \%$ & - & - & $0 \%$ & $0 \%$ \\
\hline CorpHY & - & - & - & - & - & - & $2 \%$ & $0 \%$ & - & - & $4 \%$ & $0 \%$ \\
\hline Equities & - & - & - & - & - & - & $1 \%$ & $0 \%$ & - & - & $5 \%$ & $1 \%$ \\
\hline EUR & - & - & - & - & $0 \%$ & $0 \%$ & $0 \%$ & $0 \%$ & $0 \%$ & $0 \%$ & $0 \%$ & $0 \%$ \\
\hline GBP & - & - & - & - & $10 \%$ & $4 \%$ & $8 \%$ & $4 \%$ & $18 \%$ & $3 \%$ & $10 \%$ & $4 \%$ \\
\hline JPY & - & - & - & - & $3 \%$ & $1 \%$ & $2 \%$ & $1 \%$ & $7 \%$ & $4 \%$ & $3 \%$ & $3 \%$ \\
\hline AUD & - & - & - & - & - & $5 \%$ & - & $5 \%$ & - & $7 \%$ & - & $7 \%$ \\
\hline CAD & - & - & - & - & - & $0 \%$ & - & $0 \%$ & - & $5 \%$ & - & $3 \%$ \\
\hline \multicolumn{13}{|c|}{ Panel C: Vertical Optimal Portfolios - Same Volatility - Improved Return } \\
\hline USD & $90 \%$ & $87 \%$ & $88 \%$ & $87 \%$ & $67 \%$ & $59 \%$ & $58 \%$ & $57 \%$ & $50 \%$ & $28 \%$ & $28 \%$ & $30 \%$ \\
\hline MBS & $0 \%$ & $0 \%$ & $0 \%$ & $0 \%$ & - & - & $0 \%$ & $0 \%$ & - & - & $0 \%$ & $0 \%$ \\
\hline CorpIG & $0 \%$ & $0 \%$ & $0 \%$ & $0 \%$ & - & - & $0 \%$ & $0 \%$ & - & - & $0 \%$ & $0 \%$ \\
\hline CorpHY & $0 \%$ & $0 \%$ & $2 \%$ & $0 \%$ & - & - & $11 \%$ & $5 \%$ & - & - & $21 \%$ & $1 \%$ \\
\hline Equities & $0 \%$ & $0 \%$ & $1 \%$ & $1 \%$ & - & - & $12 \%$ & $7 \%$ & - & - & $24 \%$ & $16 \%$ \\
\hline EUR & $0 \%$ & $0 \%$ & $0 \%$ & $0 \%$ & $15 \%$ & $0 \%$ & $0 \%$ & $0 \%$ & $0 \%$ & $0 \%$ & $0 \%$ & $0 \%$ \\
\hline GBP & $8 \%$ & $3 \%$ & $8 \%$ & $5 \%$ & $13 \%$ & $1 \%$ & $14 \%$ & $4 \%$ & $29 \%$ & $0 \%$ & $25 \%$ & $1 \%$ \\
\hline JPY & $3 \%$ & $2 \%$ & $1 \%$ & $1 \%$ & $4 \%$ & $5 \%$ & $4 \%$ & $6 \%$ & $21 \%$ & $13 \%$ & $2 \%$ & $13 \%$ \\
\hline AUD & $0 \%$ & $6 \%$ & $0 \%$ & $6 \%$ & - & $11 \%$ & - & $10 \%$ & - & $18 \%$ & - & $14 \%$ \\
\hline CAD & $0 \%$ & $1 \%$ & $0 \%$ & $0 \%$ & - & $24 \%$ & - & $12 \%$ & - & $40 \%$ & - & $25 \%$ \\
\hline
\end{tabular}

Note: Panel A presents the results of the BJS and vertical tests. Horizontal distance is the result of the BJS test, i.e. the difference in variance between the tested portfolio and the optimal portfolio of same return on the efficient frontier multiplied by $10 \mathrm{E} 5$. Vertical distance is the result of the vertical test, i.e. the difference in return between the tested portfolio and the optimal portfolio of same variance on the efficient frontier multiplied by 12 to provide an annualized return. Panel B (resp. Panel C) displays the horizontal (resp. vertical) optimal portfolios, with the optimal shares of each currency and asset class. *** (resp. **, *): significant at the $1 \%$ (resp. $5 \%, 10 \%$ ) statistical level.

With reasonable levels of risk $(2.01 \%)$ and return $(2.33 \%)$, pure U.S. bond investing (Columns (1)-(4)) does not reduce volatility in times of rising rates. Nor does it improve return, regardless of the diversification strategy followed.

The two other benchmark portfolios perform well in hiking periods, but they can still be significantly improved. For the portfolio based on the central banks' average allocation (Columns (5)-(8)), the risk goes from $3.07 \%$ to $2.06 \%$ by using the G4 currencies only. The corresponding currency shares are: from $63 \%$ to $87 \%$ for USD, from $4 \%$ to $10 \%$ for GBPwhich is less correlated with USD than with EUR when interest rates are rising - and from $4 \%$ to $3 \%$ for JPY. Extending the investment universe to the two non-G4 currencies (Column (6)), other asset classes (Column (7)), or both (Column (8)) reduces the risk only marginally. Optimal allocations involve marginal exposures to alternative currencies $(5 \%$ AUD in 
Columns (6) and (8)), and other assets (2\% high-yield corporate bonds, and $1 \%$ equities in Column (7)). Boosting the return value is hard: the improvement is significant at the $10 \%$ statistical level when the investment universe includes alternative asset classes. Specifically, to reach the highest accessible return value of $5.07 \%$ (Column (8)), central banks should invest in high-yield corporate bonds (5\%) and equities (7\%) as well as GBP (4\%), JPY (6\%), $\operatorname{AUD}(10 \%)$ and $\operatorname{CAD}(12 \%) .^{18}$

Let us turn to our third benchmark, the SDR-based portfolio (Columns (9)-(12)). Its risk can be significantly reduced by augmenting the share of USD government bonds in a range lying between $75 \%$ and $81 \%$, and introducing a slight proportion of U.S. high-yield corporate bonds (between $0 \%$ and $4 \%$ ) and equities (between $1 \%$ and $5 \%$ ) or Treasury bonds in AUD (7\%) or $\mathrm{CAD}$ (between $3 \%$ and 5\%). Improving the corresponding return-only at the $10 \%$ significance level-requires the inclusion of both additional currencies and asset classes, namely a portfolio invested in 30\% U.S. government bonds, $25 \%$ CAD, $16 \%$ equities, $13 \%$ JPY and AUD and 1\% high yield (Column (12)).

\section{Conclusion}

Forex reserves are key assets that central banks can mobilize in troubled times. The inability to manage reserves optimally can have far-reaching consequences. Nevertheless, some central banks are constrained by legislation forbidding them to invest in given assets or forcing them to limit specific exposures. For example, the foreign exchange reserves of the Central Bank of Chile can be invested only in "foreign currency, gold, negotiable instruments and securities or commercial paper issued or guaranteed by foreign states, central banks or foreign or international banks or financial institutions" (Banco Centrale de Chile, 2012, p. 7). On the other hand, many central banks seek to increase returns by diversifying their investments.

This paper investigates the performance of various diversification strategies with the aim of providing central banks with guidelines for optimal portfolio allocation. To this end, we determine the efficient frontier corresponding to each strategy, and compare them using two tests of portfolio mean-variance (MV) efficiency. Some strategies are accessible to most

\footnotetext{
${ }^{18}$ A slightly lower return $(4.62 \%$, see Column (7)) can be achieved without alternative currencies: $58 \%$ U.S. short term government bonds, $11 \%$ high-yield corporate bonds, $12 \%$ equities, $14 \%$ GBP and $4 \%$ JPY.
} 
central banks; others require investment restrictions to be lifted. This is why we explore the consequences of investing in four asset universes and starting from three benchmark portfolios. Moreover, we run the estimations over two samples: the full 1986-2015 period, and the rate-hiking periods.

By relying on the MV approach, our study inevitably faces the consequences of ignoring nonlinear risk. MV efficiency uses volatility as a risk measure and ignores extreme risks. This might restrict the interpretation of our full-sample results since many asset classes have nonnormal returns over the period. Alternative approaches include the three-moment and fourmoment strategies proposed by Jondeau and Rockinger (2006) and asset management techniques based on Values-at-Risk (VaR), which are commonly used in risk management (Jorion, 2007). However, each strategy relies on specific assumptions regarding the way the risk-return trade-off is to be addressed. In this regard, the traditional MV approach can reasonably be considered as a simple, middle-of-the-road option.

Our main findings can be summarized as follows. Diversification can improve the typical allocation of a central bank, particularly in terms of risk exposure. Specifically, over the whole period, the optimal risk-reducing strategy consists in increasing the share of USD, and diversifying into currencies that are weakly correlated with USD, such as GBP, AUD, and CAD. An efficient investment strategy for increasing portfolio return is based on diversified asset classes such as mortgage-backed securities, corporate bonds, and even equities. In times of rising rates, risk can be reduced through the same strategy, i.e. currency diversification notably into GBP, JPY, and AUD. In this case, however, the improvement in terms of portfolio return is harder to achieve, because it requires introducing either high-yield corporate bonds and equities, or specific currencies (JPY, GBP, AUD, and CAD) that outperform both EUR and USD when interest rates are rising. 


\section{References}

Banco Centrale de Chile (2012), "Management of Foreign Exchange Reserves at the Central Bank of Chile", available at: http://www.bcentral.cl/eng/financialoperations/pdf/reservemanagement2012.pdf

Basak G., R. Jagannathan and G. Sun (2002), “A Direct Test for the Mean-Variance Efficiency of a Portfolio", Journal of Economic Dynamics and Control 26, 1195-1215.

Beck, R. and E. Rahbari, (2011), "Optimal Reserve Composition in the Presence of Sudden Stops”, Journal of International Money and Finance, 30(6), 1107-1127.

Beck, R. and S. Weber, (2011), "Should Larger Reserve Holdings be more Diversified?", International Finance, 14(3), 415-444.

Ben-Bassat, A. (1980), “The Optimal Composition of Foreign Exchange Reserves”, Journal of International Economics 10(2), 285-295.

Bernadell C., P. Cardon, J. Coche, F.X. Diebold and S. Manganelli (2004), Risk Management for Central Bank Foreign Reserves, European Central Bank.

Borio C., J. Ebbesen, G. Galati and A. Health (2008), "FX Reserve Management: Elements of a Framework", BIS Papers No. 38.

Borio C., G. Galati and A. Health (2008), "FX Reserve Management: Trends and Challenges", BIS Papers No. 40.

Brière M., A. Chapelle and A. Szafarz (2012), "No Contagion, only Globalization and Flight to Quality", Journal of International Money and Finance 31(6), 1729-1744.

Brière M., B. Drut, V. Mignon, K. Oosterlinck and A. Szafarz (2013), "Is the Market Portfolio Efficient? A New Test of Mean Variance Efficiency when all Assets are Risky", Finance 34(1), 7-41.

Chinn M. (2014), "Emerging Market Economies and the Next Reserve Currencies", Open Economies Review 26, 155-174.

Cova P., P. Pagano and M. Pisani (2015), "Foreign Exchange Reserve Diversification and the 'Exorbitant Privilege'”, Journal of International Money and Finance, in press.

Eichengreen B. (2011), Exorbitant Privilege: The Rise and Fall of the Dollar and the Future of the International Monetary System, Oxford: Oxford University Press. 
Eichengreen B. and M. Flandreau (2014), "A Century and a Half of Central Banks, International Reserves and International Currencies”, Working Paper.

Gerard B., P. Hillion, F.A. de Roon, and E. Eiling (2012), "International Portfolio Diversification: Currency, Industry and Country Effects Revisited”, Journal of International Money and Finance 31, 1249-1278.

Goldberg L.S, C. Hull and S.K. Stein, (2013), "Do Industrialized Countries Hold the Right Foreign Exchange Reserves?”, Current Issues in Economics and Finance 19(1).

Jondeau, E. and M. Rockinger (2006), “Optimal Portfolio Allocation under Higher Moments", European Financial Management 12, 29-55.

Jorion P. (2007), Value at Risk: The New Benchmark for Managing Financial Risk, $3^{\text {rd }}$ edition, New York: McGraw-Hill.

Jones C. (2014), “Central Banks Set to Cut Debt Holdings”, Financial Times 23 June.

Kandel S. and R.F. Stambaugh (1995), "Portfolio Inefficiency and the Cross-Section of Expected Returns", Journal of Finance 50, 157-184.

Levy, H. and H.M. Markowitz (1979), “Approximating Expected Utility by a Function of Mean and Variance", American Economic Review 69, 308-317.

Li K., S. Asani and Z. Wang (2003), "Diversification Benefits of Emerging Markets Subject to Portfolio Constraints", Journal of Empirical Finance 10, 57-80.

McCauley R.N. and B.S. Fung (2003), “Choosing Instruments in Managing Dollar Foreign Exchange Reserves”, BIS Quarterly Review, March, 39-69.

McCauley R.N. and J-F. Rigaudy (2011), "Managing Foreign Exchange Reserves in the Crisis and After", BIS Papers N. 58.

Medeiros C. and S. Nocera (1988), "The Potential Role of the SDR in Diversified Currency Portfolios of Central Banks", IMF Working Paper 88/81.

Morahan A. and C. Mulder (2013), "Survey of Reserve Managers: Lessons from the Crisis", IMF Working Paper 13/99.

Pan L. and Z. Junbo (2008), “The Management of China's Huge Foreign Reserve and its Currency Composition”, Institute of Management Berlin at the Berlin School of Economics (FHW Berlin), Working Paper No.37. 
Plender J. (2014), "Follow the Swiss for Reserve Management Success", Financial Times 9 December.

Ramaswamy S. (2008), "Managing International Reserves: How Does Diversification Affect Financial Costs", BIS Quarterly Review, June, 45-55.

Wang Z. (1998), "Efficiency Loss and Constraints on Portfolio Holdings", Journal of Financial Economics 48, 359-375.

Wei L. and C. Cui (2013), "China is seeking US Assets”, Wall Street Journal, 20 May.

Wooldridge P.D. (2006), “The Changing Composition of Official Reserves”, BIS Quarterly Review, September, 25-38. 


\section{Appendix A}

Figure A1. Foreign central bank target interest rates during times of rising fed funds

\section{rates}

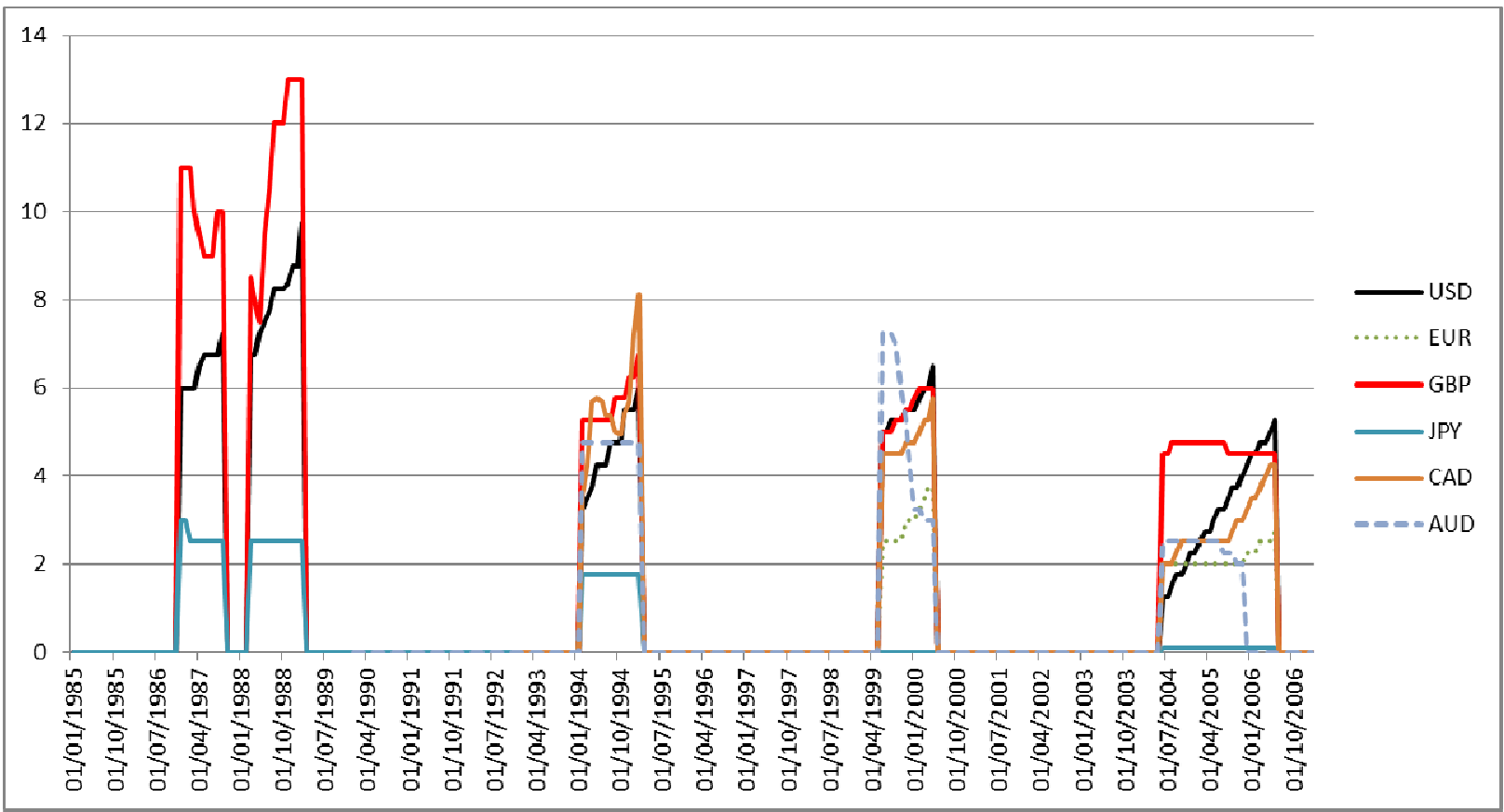

Source: Authors' calculations based on data extracted from Bloomberg (ECB main refinancing operations announcement rate, Bank of England official bank rate, Bank of Japan unsecured overnight call rate, Bank of Canada overnight lending rate, Reserve Bank of Australia cash rate target). 